\title{
Thermal Changes in Root Surface of Primary Teeth During Root Canal Treatment With Diode Lasers: An In Vitro Study
}

\author{
Bahman Seraj ${ }^{1}$, Zahra Moosavi Garmaroodi ${ }^{2}$, Nasim Chiniforush ${ }^{2}$, Sara Ghadimi ${ }^{*}$ \\ ${ }^{1}$ Dental Research Center, Dentistry Reseach Institute, Department of Pediatric Dentistry, School of Dentistry, Tehran University \\ of Medical Sciences, Tehran, Iran \\ ${ }^{2}$ Laser Research Center of Dentistry, Dentistry Research Institute, Tehran University of Medical Sciences, Tehran, Iran \\ ${ }^{3}$ Laser Research Center of Dentistry, Dentistry Research Institute and Department of Pediatric Dentistry, School of Dentistry, \\ Tehran University of Medical Sciences, Tehran, Iran
}

\section{*Correspondence to Sara Ghadimi, Department of Pediatric Dentistry, School of Dentistry, Tehran University of Medical Sciences, North Kargar St, Tehran, Iran. Postal Code: 14399- 55991. \\ Tell: +989123187866; \\ Email: sghadimi@tums.ac.ir}

Published online 17 September 2018

\begin{abstract}
Introduction: Increased temperature due to the application of laser during root canal disinfection may damage periodontium, alveolar bone, and permanent dental germ. The aim of this study was to evaluate the temperature increase of the external surface of primary roots due to the application of $810 \mathrm{~nm}$ and $980 \mathrm{~nm}$ diode lasers.

Methods: A total of 58 extracted human primary teeth were prepared and randomly divided into two groups: (a) $810 \mathrm{~nm}$ diode laser and (b) $980 \mathrm{~nm}$ diode laser. Then, each group was divided into 4 subgroups based on the location of the temperature measurement, including subgroup 1 : external root surface of primary anterior roots (A); subgroup 2: external root surface of posterior teeth at inter-root space (IS); subgroup 3: external root surface of posterior teeth at outer-root space (OS) and subgroup 4: external surface of furcation area of posterior teeth (F).

Results: The mean temperature rise in group a $\left(7.02 \pm 2.95^{\circ} \mathrm{C}\right)$ was less than that of group $b$ $\left(10.62 \pm 4.59^{\circ} \mathrm{C}\right)(P<0.001)$. Also, a significant difference was found between the laser groups in terms of the mean temperature rise of the external root surface at IS, OS and F, with higher temperature increase occurring in all points in laser b. The comparison of irradiation points in each laser showed a higher mean temperature rise for IS than OS, but this difference was only significant in group $\mathrm{b}(P<0.001)$.

Conclusion: Within the studied parameters, $810 \mathrm{~nm}$ and $980 \mathrm{~nm}$ diode lasers should be used cautiously in primary root canals because of their temperature rise during their application.

Keywords: Diode laser; Temperature rise; Primary teeth.
\end{abstract}

\section{Introduction}

The most important success factor for long-term primary and permanent root canals therapy is the disinfection of the root canals and the surrounding dentin. The use of conventional methods of root canal disinfection such as files, broaches and antimicrobial irrigating substances, due to limitations like complex and different views of root canal, presence of too many subcanals, small canal size, inaccessibility of tools and antimicrobials to root canal length and inadequate penetration into infected dentin, does not guarantee the long-term success of root canal treatment, leading to retreatment or complementary treatments. ${ }^{1-5}$ The intracanal irrigants penetrate into the dentin to a depth of $100-130 \mu \mathrm{m},{ }^{6,7}$ while many bacterial colonies exist at a depth of $1100 \mu \mathrm{m} .^{7-9}$

Introduction of lasers for root canal treatment as an auxiliary method to increase the quality of root canal disinfection has improved the success rate of pulp treatments by $99.91 \% .{ }^{10}$ In this regard, different studies have introduced Nd:YAG laser, diode lasers and erbium family lasers. Studies on these lasers have shown higher disinfection capability owing to more penetration into dentinal tubules than only using intracanal irrigation solutions. ${ }^{11-14}$

Diode lasers have a wavelength range of 810-980 $\mathrm{nm}$. These lasers have a good absorption in water and pigments. However, their absorption in hydroxyapatite is low. After absorbing laser energy in the water content of dentinal tubules, they exert their effect through photothermal effect and thermal conduction to the surrounding tissues. In addition, the laser energy destroys the pathogens during the photothermolysis process. Also, regarding the effect of laser on the hydroxyapatite present in dentin, the absorption coefficient of dentin

Please cite this article as follows: Seraj B, Moosavi Garmaroodi Z, Chiniforush N, Ghadimi S. Thermal changes in root surface of primary teeth during root canal treatment with diode lasers: an in vitro study. I Lasers Med Sci. 2018;9(4):237-242. doi:10.15171/jlms.2018.43. 
for diode laser wavelengths is low. As a result, the passing and scattering phenomena are dominant over the absorption phenomenon, and photons are absorbed at points away from the irradiation surface. This low absorption rate contributes to increased laser penetration depth. ${ }^{15,16}$ According to Beer-Lambert law and diffusion theory, laser intensity at deeper layers of tissue is reduced exponentially. Therefore, temperature rise at internal root surface above the external root surface and at less thicker areas of dentin is higher than the thicker areas. Yet, absorption of scattered photons at deep layers can increase the temperature and cause photothermal effects at deeper layers. ${ }^{17}$

Hence, due to the photothermal effect oflaser, despite many benefits of laser within the root canal, concerns exist about its side effects on dental tissue and surrounding tissues because of increased temperature on internal and external root surfaces. ${ }^{18}$ In this regard, studies have only evaluated the permanent teeth and their results have been variant depending on different factors affecting temperature rise such as laser specifications (laser type, power, frequency, wavelength, etc), study method, etc. ${ }^{2,7,14-17,19-23} \mathrm{Hmud}$ et al evaluated the effect of $980 \mathrm{~nm}(25 \mathrm{~Hz}, 2.5 \mathrm{~W})$ and $940 \mathrm{~nm}$ $(10 \mathrm{~Hz}, 4 \mathrm{~W})$ diode lasers on thermal changes of internal and external root surfaces. Their findings showed that temperature rise was lower than thermal threshold in both laser types, and both wavelengths were reported to be safe for root canal treatment. ${ }^{20}$

The structural and physiologic differences of primary and permanent teeth such as narrow root and thinner dentin as well as differences in the structure of primary and permanent dentin make the teeth susceptible to more temperature rise during laser irradiation. Moreover, since the external root surface is in contact with the surrounding tissues like the periodontium and alveolar bone, and that primary teeth are specifically related to the adjacent permanent tooth germ, this temperature rise, in the case of passing tissue damage threshold, can cause periodontal resorption and alveolar bone necrosis. ${ }^{24}$ Numerous studies have reported thermal thresholds of $7^{\circ} \mathrm{C}$ and $10^{\circ} \mathrm{C}$ for periodontal tissue and alveolar bone damage. ${ }^{19,25-27}$

This study was conducted to evaluate the temperature rise on external root surface using $810 \mathrm{~nm}$ and $980 \mathrm{~nm}$ diode lasers for disinfection of primary root canals.

\section{Methods}

After obtaining the approval from the ethical committee of Tehran University of Medical Sciences, a total of 58 extracted carious human primary teeth were selected according to the following conditions: (1) Existence of two-thirds of root length, (2) Absence of fracture in the root, (3) Lack of internal and external resorption in radiographic view, (4) Absence of perforation in pulp chamber floor.
Preparation of Samples

The samples were kept in normal saline during collection and preparation, and the solution was changed weekly. The crown of all samples was cut by diamond bur with high-speed headpiece under water cooling so that the length of all canals was $11 \mathrm{~mm}$. The canals were then cleared and flared at apical region by K-file up to \#40 with working length of $1 \mathrm{~mm}$ short of apex using step back technique (Figure 1A and 1B). Penetration of fiber laser $(200 \mu \mathrm{m}$ in diameter) into the canal was tested, and coronal area was flared as much as required for the fiber laser to enter the canal passively. Irrigation between files was performed with $1 \mathrm{~mL}$ normal saline.

\section{Classification of Samples}

The teeth were randomly divided into 2 groups, including group a: $810 \mathrm{~nm}$ diode laser and group b: $980 \mathrm{~nm}$ diode laser, 29 teeth being included in each group. Then, each group was divided into 4 subgroups, as follows (Figure 2): Subgroup 1: external surface of lingual aspect of root, including 11 primary anterior teeth (A) (11 canals) Subgroup 2: external root surface of molar teeth at inter-
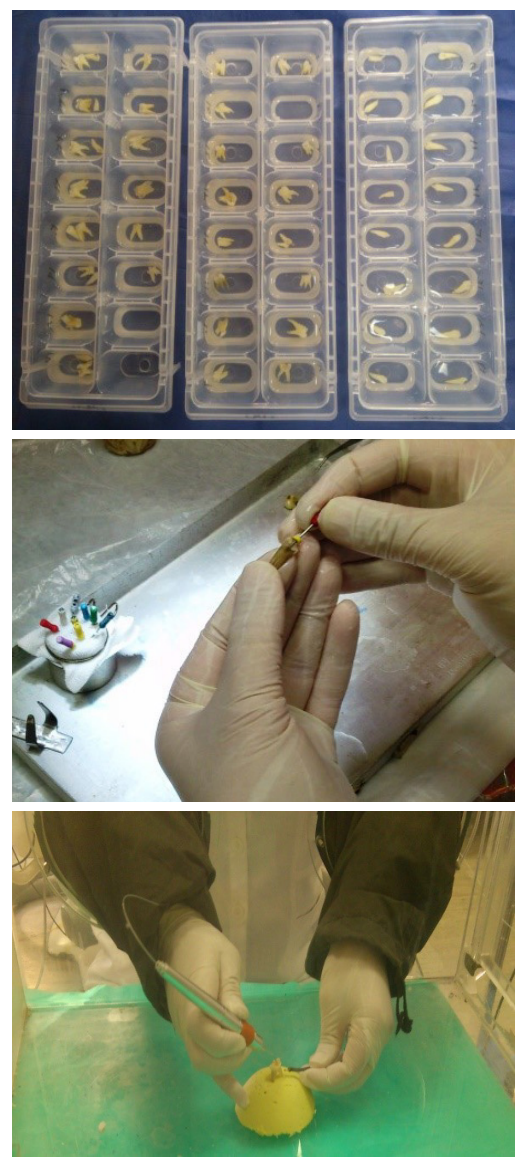

Figure 1. (A) The samples were selected and kept in normal saline during collection and preparation. (B) The canals were then cleared and flared at apical region by $\mathrm{K}$-file up to $\# 40$ with working length of $1 \mathrm{~mm}$ short of apex using step back technique. (C) All irradiation processes were carried out in incubator by one operator. 


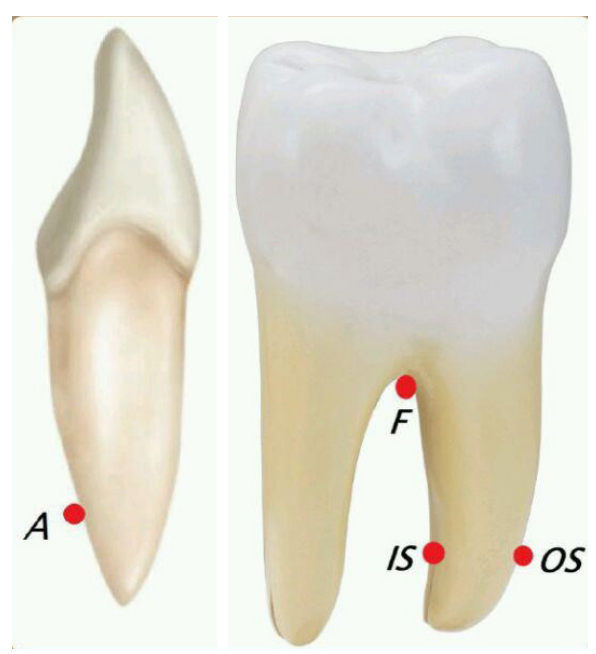

Figure 2. Classification of Samples Based on the Location of Temperature Measurement. Subgroup 1: external surface of lingual aspect of primary anterior roots (A); subgroup 2: external root surface of posterior teeth at inter-root space (IS); subgroup 3: external root surface of posterior teeth at outer-root space (OS) and subgroup 4: external surface of furcation area of posterior teeth (F).

root space (IS), including 9 teeth (27 canals)

Subgroup 3: external root surface of molar teeth at outerroot space (OS), including 9 teeth (31 canals)

Subgroup 4: external surface of furcation area in all posterior teeth (F), including 18 teeth (teeth of subgroups 2 and 3$)$.

Therefore, each canal received a code, including group, tooth number and canal number.

First, the canals were dried by paper cones, and before irradiation, the samples were placed in incubator to reach the temperature of $37^{\circ} \mathrm{C}$. An incubator (DORSA, Iran) was used to simulate the oral cavity and stabilize the base temperature and humidity of the testing environment. The temperature and humidity of incubator were adjusted at $37^{\circ} \mathrm{C}$ and $20 \%$, respectively. All stages of irradiation and temperature measurement in all samples were performed in incubator.

Temperature rise of external root surface in the first three groups (A, IS and OS) was measured by thermometer at one third middle-apical of external root surface. In the fourth group, the thermometer was fixed at external surface of furcation area of pulp chamber floor, laser was irradiated the same as other groups inside pulp chamber and thermal changes were measured (Figure 2).

\section{Laser Specifications}

Two types of diode laser were used in this study. In the first group (a): $810 \mathrm{~nm}$ diode laser (Cheese TM, Wuhan Gigaa Optronics Technology Co, LTD, China) (1.5 W, continuous mode, with endodontic fiber of $200 \mu \mathrm{m}$ in diameter) was used. ${ }^{7}$ In the second group (b), $980 \mathrm{~nm}$ diode laser (Wiser, Doctor Smile, Italy) (1.5 W, continuous mode and endodontic fiber with $200 \mu \mathrm{m}$ in diameter) was used..$^{13}$
Laser Irradiation

To create similar irradiation conditions, all irradiations were performed by one operator in a similar fashion. All irradiation processes were carried out in incubator. While using both lasers, fiber was placed at a working length of $1 \mathrm{~mm}$ short of apex (Figure 1C). Then, irradiation was started and fiber was rotated with a speed of $2 \mathrm{~mm} / \mathrm{s}$ in coronal direction. The irradiation was performed 5 times, each time for 5 seconds, with 15 seconds interval between 2 irradiations. Irradiation at furcation was done in a likewise manner.

\section{Temperature Measurement}

To stabilize thermal changes due to laser irradiation, a thermometer (NX4 K Type, HANYOUNG, Korea) with a sensitivity of $0.1^{\circ} \mathrm{C}$ was used. NX EV 1.1.0 (HANYOUNG, Korea) software was used to fix temperature changes and to prepare the relevant graphs simultaneously, with temperature registration ability at 1-second intervals (Figure 3). Temperature rise after each irradiation and its reduction following irradiation termination at intervals were recorded in each graph.

T-test was used to compare the temperature rise due to using lasers $a$ and $b$, to analyze the mean differences of temperature rise of external root surface at F, OS, IS and A points between 2 lasers and to compare irradiation points IS and OS in each laser separately. $P<0.05$ was considered significant for all statistical analyses.

\section{Results}

The mean temperature rise in group a was lower than that of group b, showing a statistically significant difference (Table 1).

Moreover, the findings revealed that at different study points, only the mean temperature rise of external root surface at point A showed no significant difference between the 2 laser groups, but there was a significant difference between the 2 laser groups at other points, more temperature rise occurring at all points in group b (Table 2). The comparison of the irradiation points IS and OS in each laser separately showed that the mean temperature rise at IS was higher than that of OS, but this

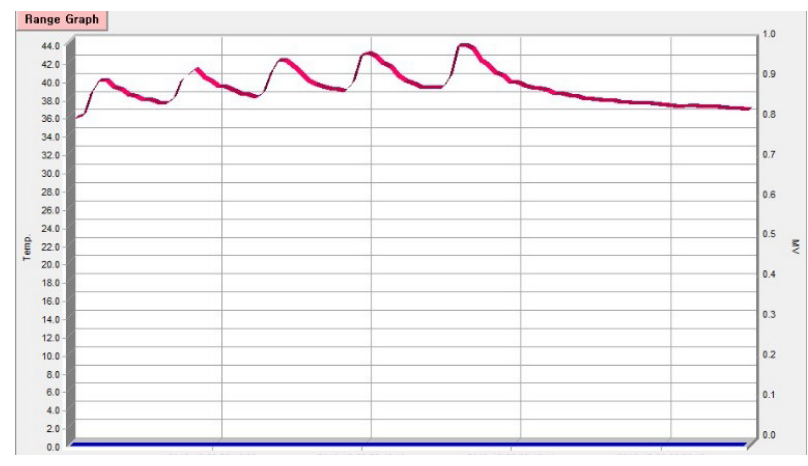

Figure 3. A Sample Graph Prepared From OS by NXEV 1.1.0 Software. 
Table 1. Mean Temperature Rise $\left({ }^{\circ} \mathrm{C}\right)$ Due to Application of 2 Types of Laser

\begin{tabular}{lcc}
\hline Laser Type & $\begin{array}{c}\text { Temperature }\left({ }^{\circ} \mathrm{C}\right) \\
\text { Mean } \pm \text { SD }\end{array}$ & $\boldsymbol{P}$ Value \\
\hline $\mathrm{a}$ & $7.02 \pm 2.95$ & $<0.001$ \\
$\mathrm{~b}$ & $10.62 \pm 4.59$ & \\
\hline
\end{tabular}

a: $810 \mathrm{~nm}$ diode laser.

b: $980 \mathrm{~nm}$ diode laser.

Table 2. Mean Temperature Rise Due to Laser Type for Thermometer Location

\begin{tabular}{lccc}
\hline $\begin{array}{l}\text { Temperature } \\
\text { Change Point }\end{array}$ & Laser Type & $\begin{array}{c}\text { Mean Temperature } \\
\text { Rise }\left({ }^{\circ} \mathbf{C}\right)\end{array}$ & P Value \\
\hline \multirow{2}{*}{ A } & a & $5.27 \pm 2.17$ & 0.69 \\
& b & $5.65 \pm 2.27$ & \\
IS & a & $8.70 \pm 3.14$ & $<0.001$ \\
& b & $16.08 \pm 3.16$ & \\
OS & a & $8.06 \pm 1.75$ & 0.001 \\
& b & $10.51 \pm 3.56$ & \\
F & a & $3.89 \pm 1.46$ & $<0.001$ \\
\hline
\end{tabular}

(A): external root surface of anterior teeth; (IS): external root surface of posterior teeth at inter-root space; (OS): external root surface of posterior teeth at outer-root space; (F): external surface of furcation area of posterior teeth.

a: $810 \mathrm{~nm}$ diode laser.

b: $980 \mathrm{~nm}$ diode laser

difference was only significant in laser b (Table 3).

Safety level (\%) of using 2 types of laser considering the thermal threshold level $7^{\circ} \mathrm{C}$ are shown in Table 4.

\section{Discussion}

In the present study, the temperature rise due to the application of $810 \mathrm{~nm}$ and $980 \mathrm{~nm}$ diode lasers was evaluated in primary root canals. Analysis of temperature rise due to intracanal laser application is necessary since it can impair adjacent periodontal tissues. ${ }^{24}$

Numerous studies have reported thermal threshold levels of $7^{\circ} \mathrm{C}$ and $10^{\circ} \mathrm{C}$ for impairing periodontal tissues and alveolar bone. ${ }^{19,25-27}$ Eriksson et al stated that the thermal threshold level of $47^{\circ} \mathrm{C}$ for 1 minute for bone health, and reported that higher temperature and more time damaged the bone. ${ }^{27}$ However, Sauk et al reported a thermal threshold of $43^{\circ} \mathrm{C}$ for the health of periodontal ligaments. ${ }^{26}$ In the present study, because of the difference between primary and permanent teeth and adjacency to permanent tooth germ and possible damage to it, the results were investigated based on the thermal threshold of $7^{\circ} \mathrm{C}$.

Since we found no study on the temperature rise resulting from laser irradiation in primary teeth, we compared our study with similar studies on permanent teeth. Disinfection and thermal changes due to laser use depend on various factors such as laser type, wavelength, laser power, irradiation duration, irradiation method, etc. ${ }^{14}$ Furthermore, many studies have evaluated the effect
Table 3. Comparison of Mean Temperature Rise Due to Laser Types at IS and OS

\begin{tabular}{lccc}
\hline Laser type & $\begin{array}{c}\text { Temperature } \\
\text { Change Point }\end{array}$ & $\begin{array}{c}\text { Mean Temperature } \\
\text { Rise }\left({ }^{\circ} \mathbf{C}\right)\end{array}$ & P Value \\
\hline \multirow{2}{*}{ a } & IS & $8.70 \pm 3.14$ & 0.34 \\
& OS & $8.06 \pm 1.75$ & \\
b & IS & $16.08 \pm 3.16$ & $<0.001$ \\
\hline
\end{tabular}

(IS): external root surface of posterior teeth at inter-root space and (OS): external root surface of posterior teeth at outer-root space. a: $810 \mathrm{~nm}$ diode laser. b: $980 \mathrm{~nm}$ diode laser.

Table 4. Safety Level (\%) of Using 2 Types of Laser Considering the Thermal Threshold Level $7{ }^{\circ} \mathrm{C}$

\begin{tabular}{lcc}
\hline Laser type & $\begin{array}{c}\text { Unsafety level (\%) } \\
\text { of Using Laser }\end{array}$ & $\begin{array}{c}\text { Safety Level (\%) } \\
\text { of Using Laser }\end{array}$ \\
\hline $810 \mathrm{~nm}$ diode laser & $47.7 \%$ & $52.3 \%$ \\
$980 \mathrm{~nm}$ diode laser & $69.7 \%$ & $30.3 \%$ \\
\hline
\end{tabular}

of different parameters of lasers and their consequent effects. ${ }^{2,7,14,17,19-22}$

To ensure the effect of the irradiation method on the disinfection rate, the protocol used in this study was taken from the studies of Schoop et al on dentinal segments, which assessed the disinfection by $810 \mathrm{~nm}$ and $980 \mathrm{~nm}$ diode lasers to be desirable, and concluded that using higher power $(1.5 \mathrm{~W}$ than $1 \mathrm{~W})$ had a better effect on reducing bacteria., ${ }^{713}$

Many studies have used different methods for oral cavity simulation. For example, in the study by Strakas et al to restore oral cavity, the teeth were placed in hot water bath $\left(37^{\circ} \mathrm{C}\right)$. But Alfredo et al and Gutknecht et al believed that using water bath was not suitable because of free flow of water and more cooling effect of water than oral cavity. ${ }^{8,19}$ In the current study, the teeth were placed in incubator, with $20 \%$ humidity and $37^{\circ} \mathrm{C}$ temperature, before and during irradiation..$^{22}$ Also, preparation of the teeth was done according to the protocol proposed by Gutknecht et al. ${ }^{28}$

Nammour et $\mathrm{al}^{29}$ and da Costa Ribeiro et $\mathrm{al}^{17}$ reported that intervals between irradiations were necessary for prevention of cumulative effect of temperature rise. In our study, this interval was considered to be 15 seconds. The irradiation method ( 5 times, each for 5 seconds with a 15 -second interval between irradiations) can be observed well in the graph. After each irradiation, the root temperature is increased and temperature is partly reduced by terminating irradiation during the interval. However, the intervals cannot fully cover the cumulative effect of temperature rise, and the height of each irradiation peak is higher than the previous peak.

In the study of Schoop et al, temperature rise for 810 $\mathrm{nm}$ diode laser at $1.5 \mathrm{~W}$ power and $15 \mathrm{~Hz}$ frequency was calculated to be $6.6^{\circ} \mathrm{C} .{ }^{7}$ The study of Gutknecht et al indicated a temperature rise due to $810 \mathrm{~nm}$ diode laser in 
groups under 1-1.5 W continuous mode irradiation to be more than $7^{\circ} \mathrm{C} .{ }^{19} \mathrm{Also}$, in our study the mean temperature rise due to $810 \mathrm{~nm}$ diode laser was reported to be $7.02^{\circ} \mathrm{C}$. The results of Alfredo et al showed a temperature rise of $6.06^{\circ} \mathrm{C}$ for $980 \mathrm{~nm}$ diode laser with $1.5 \mathrm{~W}$ and continuous mode, ${ }^{8}$ while in our study the mean temperature rise due to $980 \mathrm{~nm}$ diode laser was measured to be $10.62^{\circ} \mathrm{C}$. This higher temperature in our study can be due to the difference in dentinal thickness and, difference of primary teeth dentin. However, it should be noted that the threshold level should be considered lower owing to the presence of permanent tooth germs.

Moreover, Hmud et al evaluated the effect of 940 and 980 $\mathrm{nm}$ lasers on thermal changes of external and internal root surfaces. Their results showed that $980 \mathrm{~nm}$ laser caused higher temperature rise, which is due to better penetration power of 980 laser and its higher absorption in water. ${ }^{20}$ Similarly, in our study $980 \mathrm{~nm}$ diode laser caused higher temperature rise than $810 \mathrm{~nm}$ diode laser. Further, Hmud et al concluded that the less the thickness of dentin was the more temperature rise occurred. ${ }^{20}$ Also, in our study the more temperature rise at IS than at OS and their higher means than F can be the result of difference in dentinal thickness at these points. In line with these results, in analysis of temperature increase of external root surface due to $810 \mathrm{~nm}$ diode laser, Kreisler et al reported the impact of increased thickness on temperature rise and stated that the temperature of external root surface was reduced with an increase in dental thickness. ${ }^{12}$

The findings of our study showed lower mean temperature rise due to $810 \mathrm{~nm}$ diode laser $\left(7.02^{\circ} \mathrm{C}\right)$ than $980 \mathrm{~nm}$ diode laser $\left(10.62^{\circ} \mathrm{C}\right)$, both being higher than the safe thermal threshold level of $7^{\circ} \mathrm{C}$.

\section{Conclusion}

The results showed that under the conditions applied, it seems that both $810 \mathrm{~nm}$ and $980 \mathrm{~nm}$ diode lasers should be used with care in primary root canals. Therefore, these lasers with these parameters are not suggested to be used for root canal treatment of primary teeth due to the high temperature resulting from their application. There is a need to conduct further researches with different parameters to find out the safe results in root canal treatment of primary teeth.

\section{Conflicts of Interests}

Authors declare that there is no conflict of interest.

\section{Ethical Considerations}

The ethical committee of Tehran University of Medical Sciences approved the study (\#IR.TUMS.REC.1395.2803).

\section{Acknowledgment}

This article is part of a graduate thesis by Zahra Moosavi Garmaroodi that was carried out at the Dental School of Tehran University of Medical Sciences under the advisory guidance of Dr. Bahman Seraj and Dr. Sara Ghadimi. We have to express our appreciation to Dr. Ahmadreza Shamshiri, and Dr. Hossein Bagheri who provided expertise that greatly assisted the research.

This work was supported by Tehran University of Medical Sciences [grant number 92-03-97-24072]. Laser Research Center of Dentistry provided the laser device for this research.

\section{References}

1. Siqueira JF Jr. Aetiology of root canal treatment failure: why well-treated teeth can fail. Int Endod J. 2001;34(1):1-10.

2. Wang QQ, Zhang CF, Yin XZ. Evaluation of the bactericidal effect of Er,Cr:YSGG, and Nd:YAG lasers in experimentally infected root canals. J Endod. 2007;33(7):830-832. doi:10.1016/j.joen.2007.03.017

3. Dickers B, Lamard L, Peremans A, et al. Temperature rise during photo-activated disinfection of root canals. Lasers Med Sci. 2009;24(1):81-85. doi:10.1007/s10103-007-0526-y

4. Bago I, Plecko V, Gabric Panduric D, Schauperl Z, Baraba A, Anic I. Antimicrobial efficacy of a high-power diode laser, photo-activated disinfection, conventional and sonic activated irrigation during root canal treatment. Int Endod J. 2013;46(4):339-347. doi:10.1111/j.1365-2591.2012.02120.x

5. Friedman S, Abitbol S, Lawrence HP. Treatment outcome in endodontics: the Toronto Study. Phase 1: initial treatment. J Endod. 2003;29(12):787-793. doi:10.1097/00004770200312000-00001

6. Beer F, Buchmair A, Wernisch J, Georgopoulos A, Moritz A. Comparison of two diode lasers on bactericidity in root canals--an in vitro study. Lasers Med Sci. 2012;27(2):361364. doi:10.1007/s10103-011-0884-3

7. Schoop U, Kluger W, Moritz A, Nedjelik N, Georgopoulos A, Sperr W. Bactericidal effect of different laser systems in the deep layers of dentin. Lasers Surg Med. 2004;35(2):111116. doi:10.1002/lsm.20026

8. Alfredo E, Marchesan MA, Sousa-Neto MD, BrugneraJunior A, Silva-Sousa YT. Temperature variation at the external root surface during 980-nm diode laser irradiation in the root canal. J Dent. 2008;36(7):529-534. doi:10.1016/j. jdent.2008.03.009

9. Bystrom A, Sundqvist G. Bacteriologic evaluation of the efficacy of mechanical root canal instrumentation in endodontic therapy. Scand J Dent Res. 1981;89(4):321-328.

10. Franzen R, Gutknecht N, Falken S, Heussen N, Meister J. Bactericidal effect of a Nd:YAG laser on Enterococcus faecalis at pulse durations of 15 and $25 \mathrm{~ms}$ in dentine depths of 500 and 1,000 mum. Lasers Med Sci. 2011;26(1):95-101. doi:10.1007/s10103-010-0826-5

11. Gutknecht N, van Gogswaardt D, Conrads G, Apel C, Schubert C, Lampert F. Diode laser radiation and its bactericidal effect in root canal wall dentin. J Clin Laser Med Surg. 2000;18(2):57-60. doi:10.1089/clm.2000.18.57

12. Kreisler M, Kohnen W, Beck M, et al. Efficacy of $\mathrm{NaOCl} /$ $\mathrm{H} 2 \mathrm{O} 2$ irrigation and GaAlAs laser in decontamination of root canals in vitro. Lasers Surg Med. 2003;32(3):189-196. doi:10.1002/lsm.10148

13. Schoop U, Kluger W, Dervisbegovic S, et al. Innovative wavelengths in endodontic treatment. Lasers Surg Med. 2006;38(6):624-630. doi:10.1002/lsm.20331 
14. Bergmans L, Moisiadis P, Teughels W, Van Meerbeek B, Quirynen M, Lambrechts P. Bactericidal effect of Nd:YAG laser irradiation on some endodontic pathogens ex vivo. Int Endod J. 2006;39(7):547-557. doi:10.1111/j.13652591.2006.01115.x

15. de Souza EB, Cai S, Simionato MR, Lage-Marques JL. High-power diode laser in the disinfection in depth of the root canal dentin. Oral Surg Oral Med Oral Pathol Oral Radiol Endod. 2008;106(1):e68-72. doi:10.1016/j. tripleo.2008.02.032

16. Kaiwar A, Usha HL, Meena N, Ashwini P, Murthy CS. The efficiency of root canal disinfection using a diode laser: in vitro study. Indian J Dent Res. 2013;24(1):14-18. doi:10.4103/0970-9290.114916

17. da Costa Ribeiro A, Nogueira GE, Antoniazzi JH, Moritz A, Zezell DM. Effects of diode laser $(810 \mathrm{~nm})$ irradiation on root canal walls: thermographic and morphological studies. J Endod. 2007;33(3):252-255. doi:10.1016/j. joen.2006.09.002

18. He H, Yu J, Song Y, Lu S, Liu H, Liu L. Thermal and morphological effects of the pulsed Nd:YAG laser on root canal surfaces. Photomed Laser Surg. 2009;27(2):235-240. doi:10.1089/pho.2008.2244

19. Gutknecht N, Franzen R, Meister J, Vanweersch L, Mir M. Temperature evolution on human teeth root surface after diode laser assisted endodontic treatment. Lasers Med Sci. 2005;20(2):99-103. doi:10.1007/s10103-005-0347-9

20. Hmud R, Kahler WA, Walsh LJ. Temperature changes accompanying near infrared diode laser endodontic treatment of wet canals. J Endod. 2010;36(5):908-911. doi:10.1016/j.joen.2010.01.007

21. Klinke T, Klimm W, Gutknecht N. Antibacterial effects of Nd:YAG laser irradiation within root canal dentin.
J Clin Laser Med Surg. 1997;15(1):29-31. doi:10.1089/ clm.1997.15.29

22. Strakas D, Franzen R, Kallis A, Vanweersch L, Gutknecht N. A comparative study of temperature elevation on human teeth root surfaces during Nd:YAG laser irradiation in root canals. Lasers Med Sci. 2013;28(6):1441-1444. doi:10.1007/ s10103-012-1203-3

23. Fransson H, Larsson KM, Wolf E. Efficacy of lasers as an adjunct to chemo-mechanical disinfection of infected root canals: a systematic review. Int Endod J. 2013;46(4):296307. doi:10.1111/iej.12003

24. Abad-Gallegos M, Arnabat-Dominguez J, Espana-Tost A, Berini-Aytes L, Gay-Escoda C. In vitro evaluation of the temperature increment at the external root surface after Er,Cr:YSGG laser irradiation of the root canal. Med Oral Patol Oral Cir Bucal. 2009;14(12):e658-662.

25. Nammour S, Kowaly K, Powell GL, Van Reck J, Rocca JP. External temperature during KTP-Nd:YAG laser irradiation in root canals: an in vitro study. Lasers Med Sci. 2004;19(1):27-32. doi:10.1007/s10103-004-0303-0

26. Sauk JJ, Norris K, Foster R, Moehring J, Somerman MJ. Expression of heat stress proteins by human periodontal ligament cells. J Oral Pathol. 1988;17(9-10):496-499.

27. Eriksson AR, Albrektsson T. Temperature threshold levels for heat-induced bone tissue injury: a vital-microscopic study in the rabbit. J Prosthet Dent. 1983;50(1):101-107.

28. Gutknecht N. Lasers in endodontics. J Laser Health Acad. 2008;4:1-4.

29. Nammour S, Rocca JP, Keiani K, et al. Pulpal and periodontal temperature rise during KTP laser use as a root planing complement in vitro. Photomed Laser Surg. 2005;23(1):10-14. doi:10.1089/pho.2005.23.10 